\title{
AMÉRICA LATINA: ÚLTIMOS ESTUDIOS EN ECONOMÍA Y. SOCIOLOGÍA POLÍTICA
}

\author{
Isabel Ortiz \\ London School of Economics
}

Resum

L'article presenta un resum de les tendències $i$ de la literatura anglosaxona sobre l'Amèrica Llatina contemporania, tot centrant-se en tres temes: desenvolupament, estats $i$ democràcia. Sobre desenvolupament, es critiquen les teories dependentista i neolliberal, i es mostren les bases d'alguns estudis de la nova economia politica. Sobre l'estat, es comenten els debats entorn del capitalisme d'estat i la seva autonomia. Sobre democràcia, es critiquen les teories lliberal $i$ marxista, $i$ s'analitzen alguns estudis recents sobre la transició.

Resumen

El articulo presenta un resumen de las tendencias y de la literatura anglosajona sobre la América Latina contemporánea, centrándose en tres temas: desarrollo, estados y democracia. Sobre desarrollo, se critican las teorias dependentista y neoliberal, y se muestran las bases de algunos estudios de la nueva economía politica. Sobre el estado, se comentan los debates en torno al capitalismo de estado y su autonomía. Sobre democracia, se critican las teorias liberal y marxista, y se analizan algunos estudios recientes sobre la transición.

Abstract

The article is a summary of the trends and the anglosaxon literature on contemporary Latin America, focus on three subjectes: development, states and democracy. With regard to development, a critique on dependency and neoliberal theories is made, discribing the background of some studies carried out on economic policy. Concerning the state, the debates around state capitalism and autonomy are expounded. On democracy, Marxist and liberal theories are discussed, analysing some recent studies regarding transition.

En este artículo se revisará parte de la literatura anglosajona sobre América Latina en tres temas fundamentales: desarrollo, estado y democracia. La bibliografía que se ofrece al final señala estudios recientes sobre otros temas, pero no se han comentado por motivo de espacio. 
«Papers»: Revista de Sociologia

\section{DESARROLLO EN AMÉRICA LATINA}

A través de las últimas décadas podemos observar un abuso de la palabra «desarrollo», de manera que se hace difícil entender su significado en el contexto de países concretos.

Para comenzar, la delineación de la línea entre desarrollo y subdesarrollo no es una tarea fácil. Tradicionalmente, se ha venido utilizando el PNB per cápita como índice. Sin embargo, éste no muestra las diferencias en renta individual - véase el caso de Venezuela, que muestra uno de los más altos $\mathrm{PNB}$ pero también uno de los mayores índices de desigualdad. Otro de los problemas del PNB es que las estadísticas oficiales no contienen datos sobre la economía sumergida ni del llamado "sector tradicional», actividades que producen de un $20 \%$ a un $40 \%$ del PNB en América Latina. En tercer lugar, la paridad de la moneda nacional con el dólar es frecuentemente modificada, lo que de nuevo hace del PNB una mala medida para el desarrollo. Si en vez de un criterio económico utilizamos uno social, comparando estándards de vida (educación, sanidad, dieta, etc.), las estadísticas nos muestran, por ejemplo, que Cuba o Costa Rica tienen un grado de desarrollo muy superior, aun cuando económicamente son países atrasados.

En líneas generales, la historia de los estudios sobre «desarrollo» en Latinoamérica comienza tras la Segunda Guerra Mundial, cuando los representantes de las naciones aliadas mantuvieron dos conferencias en un par de pequeñas ciudades norteamericanas: Dumbarton Oaks y Bretton Woods. Después del conflicto militar, la misión era estabilizar el mundo. La asunción era que ello se conseguiría a través del desarrollo económico y la intervención del estado. Así nacieron FAO, WHO, UNESCO, FMI y el BIRD (luego Banco Mundial); con estas organizaciones, la retórica de la ayuda se convirtió en la retórica del «desarrollo». Basándose en los estudios sobre Europa y USA de Rostow, Clack y otros, la idea era que la transición del subdesarrollo al desarrollo se producía a través de una serie de etapas que todas las naciones debían cumplir. Así, se trataba de acabar con los obstáculos internos en Latinoamérica, y suplir algunos de los componentes ausentes, tales como capital y técnica.

Hacia la mitad de los años 50, América Latina no había mejorado su situación. Autores de orientación marxista comenzaron a criticar los modelos liberales de desarrollo y teorías tales como la de Hecksher-OhlinSamuelson, que ha inspirado el comercio internacional desde la Segunda Guerra Mundial. Autores como R. Prebish, S. Amin, I. Wallerstein, A. G. Frank y otros concluyeron, en líneas generales, que el crecimiento del mundo desarrollado bloqueaba el desarrollo del Tercer Mundo (para una explicación del debate marxista desde sus orígenes, vid. Palma, 1981, y 
América Latina: últimos estudios en economía y sociología política

Booth, 1981). América Latina se encontraba en una situación de dependencia con respecto al Primer Mundo, lo que hace que los modelos de desarrollo basados en la experiencia europea y americana sean inaplicables al Tercer Mundo. R. Prebish, director de la CEPAL, concluyó la necesidad de incrementar el rol de la demanda interna y reducir el peso de la competencia internacional; para ello, ideó una política de "Industrialización a través de la Substitución de Importaciones»-ISI- como alternativa antiliberal y no marxista de desarrollo para América Latina.

La teoría de dependencia ha sido criticada desde múltiples puntos de vista. Quizás la crítica más obvia fue el fracaso de las políticas ISI, aplicadas a la Argentina de Perón, al Brasil de Goulart, y otros. Las causas fueron el poder de las oligarquías, el desequilibrio de las balanzas de pagos como consecuencia del proteccionismo, la penetración del capital extranjero y el desempleo - desempleo que significó tensión social más caída de la demanda doméstica deseada - (Abel \& Lewis, 1984; Roxborough, 1979).

El pensamiento liberal recogió la crítica dependentista, y - presionado por factores como la revolución cubana- creó una teoría alternativa, menos economicista y con pretensiones sociales y políticas: se trata de las teorías de modernización, que inspiraron las ayudas americanas de los años 60 y 70 («Alianza para el Progreso», etc.). Sin embargo, la crisis de los 80 alteró el espíritu de solidaridad y cooperación de tales ayudas. La era Reagan y la deuda internacional han cambiado el interés por el desarrollo, por la retórica de la estabilización. La impaciencia y el escepticismo respecto a las búsquedas de desarrollo autóctono han conducido a la concesión de ayudas por parte del Banco Mundial y del Fondo Monetario Internacional, si y sólo si se aceptan los principios neoliberales de organización del estado y la economía. Los programas que tales agencias ofrecen para la estabilización suponen años de recesión y austeridad, difícilmente compatibles con las recién nacidas democracias latinoamericanas. Así, la mayor parte de naciones se encuentran en una encrucijada de difícil solución.

El mundo académico ha reflejado el mismo cansancio por las teorías dependentistas, incluso dentro del mismo pensamiento marxista. Uno de los pioneros fue el malogrado Bill Warren, que ya en los 70 acusaba a los teóricos de la revolución del Tercer Mundo de «niños burgueses con sentimientos de culpa liberales», y a la teoría de dependencia de "confuso sentimentalismo sin base empírica». Para Warren, el problema del marxismo actual se remonta a Lenin, que vendió una rebaja del programa revolucionario a las colonias, pactando con la incompetente burguesía local nacionalista y olvidando que el estadio del desarrollo capitalista es necesario para el futuro bienestar del comunismo (Warren, 1980). Sin la agresividad de Warren, podría decirse que «la nueva economía política» de los 80 (Evans \& Stephens, 1988) ha intenta- 
do revisar detalladamente el presente y pasado de América Latina, evitando prejuicios y corrigiendo generalizaciones abusivas. Más que propuestas idealistas, lo que se pretende es la comprensión de las diferentes situaciones de las distintas naciones, de manera que a la hora de la toma de decisiones, éstas sean realistas y no dañen más al sub-continente. A través del análisis de situaciones concretas, con énfasis en la fundamentación empírica, la nueva literatura ofrece una visión notablemente diferente de Sudamérica.

Que la retórica del desarrollo haya sido muy útil para las naciones de la OECD para la exportación de capital y material militar, así como para la explotación de mano de obra barata del Tercer Mundo, es una denuncia muy adecuada ante el ethos apolítico de la literatura económica liberal. Sin embargo, algunas naciones han sabido tomar provecho de ello. Tal es el caso de las llamadas NIC (Naciones de Nueva Industrialización: Taiwan, Corea del Sur, Hong-Kong). Ello ha conducido a algunos autores a hablar del «Fin del Tercer Mundo" (N. Barley, 1987). La teoría parece un tanto optimista en cuanto que las condiciones bajo las cuales dichas naciones se han desarrollado no van a repetirse para una Latinoamérica endeudada internacionalmente. Sin embargo, las NIC pueden ser una lección de pragmatismo político. Las naciones del Tercer Mundo tienen dos opciones: integrarse de una manera $u$ otra en la economía internacional, o no. Los años 80 han sido una década de apertura de los nacionalismos (caída de regímenes militares en América Latina, Perestroika en el bloque del Este), y con ello se ha producido una extensión del mercado internacional. Sin embargo, se trataría de que la transición fuera realizada inteligentemente, sin permitir que el neoliberalismo establezca lazos de dependencia irreversibles. La alternativa nacionalista sigue siendo posible, pero depende de la extensión, locación y riqueza del país -así, no es lo mismo China que Nicaragua.

Volviendo a la crítica de las teorías dependentistas, no hay ninguna conexión lógica entre dependencia y subdesarrollo. En un extremo tenemos naciones independientes y desarrolladas, como USA, y naciones dependientes y subdesarrolladas, como Uruguay. Pero también se dan los casos de países independientes y subdesarrollados como China, y de países dependientes pero desarrollados, como las NIC. Se dan muchas posibilidades de dependencia: de la inversión extranjera, de una sola exportación - por ejemplo, Venezuela depende de su petróleo-, de un país - como México de USA-, de la importación de tecnología, etc. La independencia tiene sus costos: las naciones independientes son menos eficientes que las naciones especializadas y con un lugar en el mercado internacional. Cierta dependencia puede ser útil.

La introducción de compañías multinacionales (MNC), por ejemplo, puede ser beneficiosa para el país si el estado actúa adecuadamente. 
Las MNC, a fin de cuentas, proporcionan empleo, nueva tecnología, acaban con la producción nacional si ésta es ineficiente, y los estados reciben altos beneficios a través de los impuestos a la MNC. La MNC puede ser beneficiosa, pues, si se controla, si en vez de hundir la industria nacional la moderniza - lo que se consigue a través de políticas de fomento a la inversión-y si utiliza mano de obra de manera formal - y no sumergidamente. Un método puede ser el control del $51 \%$ de las acciones; aunque esta política solo será aceptada por la MNC si el mercado doméstico es lo suficientemente grande y está protegido (como en la URSS, o quizás Brasil). En el caso de que la MNC esté ya establecida o que el mercado interno sea pequeño, y que el estado desee alterar el comportamiento de la MNC, la MNC accederá a cambiar si la propuesta del gobierno no disminuye el beneficio de la corporación. Por ejemplo, si el estado desea tener acceso a la tecnología, o situar una factoría en determinada zona, puede obtenerlo si a cambio ofrece protección fiscal, garantías de convenios con los sindicatos, etc.; tal ha sido el caso con la industria farmacológica en Brasil (Evans, 1979). En México, el estado intentó similarmente el control de la actuación de las MNC, sin mucho éxito. Sin embargo, lo que no logró a través de la regulación directa de las MNC, lo logró cambiando la estructura de la producción industrial nacional. En el caso de la industria automovilística, el estado privatizó las factorías ineficientes, quedándose, sin embargo, con una. De esta manera, podía controlar los precios del mercado vendiendo los coches «del estado» mas o menos baratos; esto fue un arma de presión contra la MNC, que accedió a las peticiones gubernamentales (Bennet \& Sharpe, 1985).

El problema actual de América Latina, sin embargo, es atraer a las MNC. El aumento del proteccionismo en las naciones OECD, la caída de precios de materias primas, la diferencia tecnológica entre el Primer y Tercer Mundo y la escasez de capital inversor son importantes limitaciones para el desarrollo de América Latina. El Tercer Mundo ha perdido incluso su ventaja comparativa -mano de obra barata-: las MNC se están trasladando a las naciones desarrolladas, para penetrar sus mercados protegidos. En los años 80 y 90 , la competición del mercado internacional no ha sido sólo por la producción más barata, sino fundamentalmente por nuevos mercados. Los beneficios que antes se obtenían de la división internacional del trabajo hoy se obtienen de la automatización tecnológica (Strange, 1988). Esto supone un cambio en la estrategia desarrollista: los planes teorizados en los años 60 no son adecuados hoy.

Han de buscarse nuevas medidas para impedir la marginalización total de América Latina de la economía mundial. Diferentes autores y organizaciones han apuntado: diversificación de las exportaciones en productos no tradicionales, comercio intraregional, mejora de la eficiencia en la producción nacio- 
nal (desde privatización hasta medidas de control de la evasión de capital), y la renegociación de la deuda. Las MNC podrían ser atraídas si los mercados sudamericanos fueran lo suficientemente atractivos. Y éstos podrían serlo si se adoptaran las medidas proteccionistas adecuadas, junto con una política más igualitaria que incrementara el poder adquisitivo de la población, en vez de liberalizar radicalmente la economía - tal como el FMI propone.

La deuda externa no ayuda en esta situación (para una explicación del proceso de endeudamiento, vid. O'Brien, 1986; Thorp \& Whitehead, 1987; Strange, 1988; Kahler, 1985). Hay varias soluciones a la crisis: a) seguir las indicaciones señaladas por el FMI, la banca internacional y la OECD, sin mirar las consecuencias que pueda tener para el futuro desarrollo del país; b) no pagar, amenazando al mundo desarrollado con un cartel tercermundista (F. Castro), y c) pagar, pero exigiendo condiciones. Si los gobiernos latinoamericanos consideran conveniente la posibilidad de nuevos préstamos, inversión extrajera, etc., la deuda se ha de comenzar a pagar. Sin embargo, las condiciones de pago pueden ser ampliamente modificadas, dependiendo de la fortaleza de los deudores en su petición. Es por ello que se ha preferido amenazar con un cartel, pero sin formarlo realmente - los grandes deudores (Brasil, México, Argentina) han obstaculizado las negociaciones (Milivojevic, 1985)-. Aun así, los costos del ajustamiento no afectarán a toda América Latina por igual. Las naciones pequeñas se encuentran limitadas por la caída de precios de materias primas, y difícilmente podrán industrializarse debido a que sus mercados nacionales son reducidos (Kahler, 1985). Una vez más, la diversidad de América Latina hace que ninguna teoría pueda generalizarse a todos sus países.

\section{EL ESTADO EN AMÉRICA LATINA}

Uno de los debates centrales en los últimos años ha sido generado en torno a la especifidad o no del estado en el Tercer Mundo. En América Latina, el estado ha jugado un rol crucial en el desarrollo económico del área. No sólo se ha implicado en las actividades tradicionales de intervención - esto es, infraestructura e industria deficitaria - sino que, a diferencia del mundo occidental, los estados latinoamericanos han intervenido en áreas tales como extracción mineral, petróleo, acero, armamento y otras. En algunas naciones del Tercer Mundo, las empresas estatales constituyen más de la mitad del total de la inversión nacional (Teichman, 1988). Algunos autores comenzaron a teorizar sobre el «capitalismo de estado», considerando que ninguna noción de libre mercado es adecuada para analizar América Latina. La centralidad del estado en el área ha sido generalmente explicada como 
América Latina: últimos estudios en economía y sociología política

resultado de la falta de una burguesía extensa y dinámica, dado el pasado colonial (Canak, 1984).

Sin embargo, el considerar que la naturaleza del estado latinoamericano es diferente de la de los estados occidentales es altamente cuestionable. En primer lugar, la teoría del «capitalismo de estado» es una reacción contra la visión liberal del estado como no intervencionista. No obstante, está por demostrar que tal haya sido el caso. Al contrario, recientes análisis históricos muestran que la intervención estatal en Occidente ha sido mucho más importante de lo que se pensaba (Hardach, sobre Alemania; Johnson, sobre Japón). El problema ha sido confundir una predilección liberal -el no intervencionismo- con el desarrollo histórico del Primer Mundo. En segundo lugar, lo que es importante no es el tamaño del sector estatal, sino su impacto en la economía. Tras la Segunda Guerra Mundial, a pesar de que las naciones latinoamericanas incrementaron el número de medidas proteccionistas, los precios mundiales aún afectaban notablemente los precios internos. Un ejemplo más actual es la presente vulnerabilidad de las economías latinoamericanas a los cambios del mercado internacional. Así, en términos de comparaciones internacionales, el concepto de «capitalismo de estado » no parece adecuado (Roxborough, 1985). En tercer lugar, el rol dinámico de las clases medias ha sido subestimado. Recientes estudios neomarxistas en la materia muestran la existencia de una «triple alianza» entre capital exterior, estado y burguesía (Evans, 1979; Becker, 1983). Así, aunque los estados latinoamericanos presenten un desarrollo diferente del de las sociedades occidentales, no parece que haya ninguna buena razón para tratarlos como entidades distintas.

La cuestión de la autonomía del estado es el segundo debate importante que ha dominado el mundo académico en los últimos años. Algunos autores observan los estados latinoamericanos como dependientes de algún grupo externo (clase dominante, capital multinacional, otras naciones) o todos ellos combinados. Otros autores ven al estado con cierto grado de autonomía respecto a grupos económicos y sociales. La polémica entronca con el viejo y complejo debate teórico sobre la naturaleza del estado. En líneas generales, encontramos tres modelos: el instrumental (un grupo utiliza al estado como instrumento para sus intereses), el modelo funcional (el estado existe para la reproducción del sistema) y el modelo del estado autónomo (el estado es una institución con sus propios intereses y cuyo rol es coordinar los diferentes grupos de presión de una sociedad). Revisaremos los distintos modelos a la luz de recientes estudios sobre Latinoamérica.

La primera cuestión a analizar es si algún grupo económico o social controla el estado, es decir, si el modelo instrumental es adecuado. En México hay fuertes conexiones entre las élites económica y política; sin embargo, más 
que la primera influenciando la segunda, la relación parece inversa: los políticos «se retiran a los negocios». Desde los inicios del s. xx las élites políticas de México han sido reclutadas entre las clases medias -y la tendencia a ello se incrementa con el paso de las décadas-. Los tecnócratas son socializados dentro del PRI, y no en un medio de alta burguesía. Así, en términos de escolarización y background social hay una clara separación entre élites industriales y políticas. Ello no significa que no compartan intereses; industria y finanzas están fuertemente representados en el gobierno debido al rol que comparten en el desarrollo del país. Presiones externas pueden reforzar la unión entre el estado y las clases dominantes contra las demandas de otros gobiernos extranjeros. No obstante, la élite política y la económica parece estar fundamentalmente separadas (Smith, 1979; Story, 1986). En Brasil se ha señalado también una clara separación entre el estado y las élites industriales y financieras, tanto en términos ideológicos como en orígenes sociales (McDonough, 1981).

Si bien las élites económicas no dominan a las políticas en Brasil y México, pudiera darse una coincidencia de intereses que, de algún modo, no invalidaría el modelo instrumental. Hay algunas evidencias de crecimiento simbiótico de la burguesía y del estado mexicano. Sin embargo, el problema surge al intentar ver el estado como un todo coherente, dado que varios de sus departamentos y organismos tienen intereses diferentes, y llevan a cabo proyectos contradictorios entre sí (Teichman, 1988). Por otra parte, tampoco la élite económica está unida; siguiendo el ejemplo de México, la deuda externa de los 80 ha llevado a fuertes tensiones entre el capital industrial y financiero. El caso parece ser que, en períodos de estabilidad, los intereses de la clase dominante (o fracción de ella) tienden a coincidir con los del estado (crecimiento, desarrollo); sin embargo, en tiempos de crisis los intereses divergen: el principal interés de los estados pasa a ser la estabilidad política y la solución de la crisis (Roxborough, 1985). Tal es el caso general con la presente deuda externa en Latinoamérica.

Observemos ahora la posibilidad del capital multinacional y otros gobiernos controlando el estado. En Brasil, Evans concluye que el poder de las multinacionales influenciando en política es variable; el autor recoge diversos casos en los cuales el estado modeló la actuación de las multinacionales (Evans, 1979). Sin embargo, no hemos de olvidar la diversidad de los países latinoamericanos. Mientras que Brasil ha diversificado exitosamente su economía, México ha sido lo contrario (62\% de la inversión extranjera es de origen USA; Whitehead, 1986). Así, México es más vulnerable y dependiente de la influencia norteamericana. Aun en este caso, el estado tiene cierto poder para alterar la actuación de multinacionales (Bennet \& Sharpe, 1985) (ver la sección sobre «desarrollo»). 
América Latina: últimos estudios en economía y sociología política

Estos estudios muestran que el modelo instrumental de estado no es adecuado para el análisis de los países estudiados. Incluso en el caso de una «triple alianza», tal como ha propuesto Evans para Brasil y - de una manera similar-Becker para Perú, el estado no aparece como el instrumento directo de ningún interés externo. Al contrario, el estado es un actor político con sus intereses particulares con los que presionar a otros grupos (impuestos, perpetuación de burocracias, gasto social, etc.). Aun así, los estados latinoamericanos están limitados por factores estructurales, tales como la competitiva economía internacional. En este sentido, las tesis dependentistas parecen adecuadas si se toman relativamente, esto es, si se interpretan en el sentido de que el estado es dependiente de factores externos, pero no es una entidad absolutamente pasiva. Siendo uno de los actores importantes en el juego político, el estado tiene cierto espacio para maniobrar y conseguir beneficios de otros poderes.

Aceptando que no hay un control directo, los modelos autónomos del estado son más adecuados. Ello no significa olvidar la capacidad de diversos actores políticos (militares, élites financieras/industriales, sindicatos, agencias internacionales, otros gobiernos...) de afectar decisivamente los procesos políticos. El poder del estado se basa en el éxito económico, habilidad para pactar con los diferentes grupos de presión, legitimidad y coerción, así como de la ausencia de desafíos internos/externos. Dado que el poder en este contexto es relacional, toda autonomía debe ser definida como un poder relativo frente a otros actores políticos (Hamilton, 1982). El estado puede formar alianzas (por elección o por fuerza) con alguno/s de los grupos de presión. Cada uno de ellos ofrecerá ciertas posibilidades y ciertas limitaciones al poder del estado. La ventaja de los modelos autónomos es que nos permiten examinar más claramente el juego de alianzas/antagonismos del estado en relación a otros grupos, esto es, la balanza de poder en cada caso particular.

El modelo funcionalista ilumina otros aspectos. El funcionalismo parece capturar correctamente la esencia del estado, pero el problema reside en probar la teoría empíricamente y no a través de aserciones tautológicas ( $\ll \mathrm{La}$ sociedad crea el estado para perpetuar el orden y así el interés del estado es mantener el sistema»). En Latinoamérica, el alto funcionariado parece fundamentalmente comprometido en mantener el orden existente; paradójicamente, esto significa perpetuar también las contradicciones presentes (Teichman, 1988). Los estado latinoamericanos están lejos de ser coherentes internamente; las agencias y ministerios usualmente han desarrollado intereses distintos y adoptan políticas contradictorias (Bennet \& Sharpe, 1986; Teichman, 1988). Ello no es una particularidad de los estados latinoamericanos, sino que es común a los países occidentales (Offe, 1984). Por otra parte, la búsqueda de soluciones rápidas a los conflictos del presente ha comportado nuevas con- 
«Papers»: Revista de Sociologia

tradicciones en múltiples ocasiones. Medidas adecuadas a corto plazo pueden tener malas repercusiones a medio/largo plazo; por ejemplo, muchas de las nacionalizaciones realizadas en Latinoamérica fueron hechas para complacer a sindicatos y al sector privado nacional, sin embargo, con el tiempo se han convertido en una carga para el estado (Ames, 1987).

En resumen, el estado es una institución de gobierno con un grado relativo de coherencia interna y un también relativo grado de autonomía externa. Por ello, modelos funcionalistas y autónomos parecen más adecuados para su análisis. No obstante, no hemos de olvidar condicionamientos al estado, tanto de grupos de presión internos (militares, sindicatos, élites industriales/financieras) y externos (otros gobiernos, capital extranjero, organizaciones internacionales - Banco Mundial, Fondo Monetario Internacional, etc.). Generalizar sobre América Latina es imposible: cada país presenta un distinto grado de presión por cada uno de estos grupos (por ejemplo, compárese la influencia militar de USA sobre Panamá y Brasil).

\section{DEMOCRATIZACIÓN EN AMÉRICA LATINA}

Sin lugar a dudas, la gran estrella en los estudios de los años 80 sobre América Latina ha sido la transición democrática. Después de más de quince años de dictaduras militares, las naciones del subcontinente han comenzado la apertura política. El corazón de la polémica gira en torno a la cuestión de cuáles son las condiciones para la consolidación de la democracia. El pensamiento liberal clásico considera que cuando más económicamente avanzada es una sociedad, más posibilidades tiene de ser demócrata (Lipset, 1959). Al contrario, el pensamiento marxista teorizó que para conseguir un crecimiento económico acelerado, un gobierno necesita concentrar capital para mantener una alta tasa de inversión. Ello significa que el estado debe mantener desigualdades de renta - es decir, reducir los salarios al mínimo-, y con ellas, regímenes autoritarios para reprimir quejas populares. Para O'Donnell, la teoría liberal que une desarrollo y democracia es errónea, dado que precisamente Latinoamérica estaba desarrollándose en los 70 gracias a que regímenes militares altamente represivos eliminaban toda actividad política, definiendo problemas económicos y sociales como cuestiones técnicas y administrativas (O'Donnell, en Collier (ed.) 1979).

Ambas teorías acusan el mismo defecto: determinismo económico. La teoría liberal parece ignorar que el crecimiento económico puede producir democratización, pero no necesariamente. Por otra parte, la llamada «teoría del autoritarismo burocrático" de O'Donnell es errónea en algunas de sus premisas. En primer lugar, es fruto de considerar la etapa de dictaduras mili- 
tares en Sudamérica como un nuevo modelo de acumulación capitalista. Sin embargo, si bien las dictaduras abren una nueva etapa política, económicamente no son más que un reforzamiento del tipo de acumulación iniciado tras la Segunda Guerra Mundial. Desde los años 40, ha habido un lento pero continuado crecimiento (5.5\% de incremento anual $\mathrm{PNB}$, la esperanza de vida ha pasado de 56 años a principios de los 60 a 64 años a principios de los 80 , etc.); es decir, la visión de O'Donnell de súbito cambio desarrollista con el autoritarismo es fruto de una falta de perspectiva histórica a la hora de analizar la crisis coyuntural de los 60 (Serra, en Collier, 1979). Por otra parte, no hay ninguna duda respecto a que amplios sectores de la sociedad fueron reprimidos y los salarios nominales reducidos; sin embargo, hubo un incremento constante en los salarios reales y, lo más importante, altas tasas de movilidad social. Es decir, que el empeoramiento de las condiciones de vida observable en las estadísticas no se corresponde con la vida de los individuos en sociedad, que fueron mejorando sus posiciones progresivamente (Morley, 1982).

Una visión más política señalaría que el crecimiento económico no es el único factor clave para la estabilidad política. La institucionalización de nuevos grupos participantes en el juego político y la concertación entre todos los grupos sociales y económicos son piezas claves para la democratización. $\mathrm{O}$ los diferentes grupos cooperan (pactos sociales), o, en el caso de movilizaciones incontroladas (sea porque sindicatos, grupos nacionalistas, etc. no han sido incorporados a la arena política, o bien por insatisfacción - revueltas estudiantes, huelgas, etc.- -), entonces se producirá la represión para mantener la estabilidad política («pretorianismo»-Huntington, 1968-). La democracia se caracteriza por su capacidad de pactar los conflictos políticos. Por ello, C. Gillispie señala que un análisis de la transición democrática en América Latina debería centrarse en los tres puntos principales del conflicto político:

a) Las relaciones civiles-militares (la democracia exige o que los militares pierdan poder, o bien que se incorporen al servicio de la sociedad civil). Argentina es un ejemplo de relaciones hostiles en la transición; los juicios han causado rebeliones militares, de manera que Menen terminó concediendo la amnistía. Brasil es un ejemplo de lo contrario, debido a que la transición ha sido «controlada desde arriba» (O'Brien \& Cammarck, 1985).

b) Las relaciones entre el gobierno y la oposición (la apertura democrática da pie al debate político, pero la oposición no debe olvidar que el exceso de crítica y divisiones internas pueden debilitar al gobierno civil frente al poder militar). En Argentina, las relaciones gobierno-oposición han sido tensas y difíciles, de manera que el gobierno de Alfonsín no pudo pactar con ningún partido con cierta constancia como para realizar una política cohe- 
rente. Lo mismo ha sucedido en Brasil, donde las elecciones federales dieron una gran victoria a la oposición frente al gobierno central de Sarney, de manera que la coordinación y ejecución de políticas ha sido muy difícil debido al boicot mutuo - y la tendencia parece repetirse con el nuevo presidente, Collar de Mello-. Sin embargo, Brasil presenta una situación relativamente mejor a la argentina, debido a que ha mantenido una «élite tecnocrática» aislada de presiones coyunturales y que sigue planificando el desarrollo a largo plazo del país (Thorp \& Whitehead, 1987).

c) Las relaciones entre el estado, empresarios y sindicatos (concertación social). En Argentina, se produjeron momentáneamente en 1985 y 1988, con los Planes Austral y Primavera, deshaciéndose rápidamente debido a las fuertes medidas de austeridad de los programas de estabilización. Los sindicatos argentinos están fundamentalmente controlados por peronistas, con lo cual la cooperación con Alfonsín fue casi nula. En Brasil también han habido varias huelgas generales debido a la presión de los Planes Cruzado y Verao (1986 y 1988). Como en Argentina, la fuerte represión militar hizo que muchos de los líderes sindicales «desaparecieran», de manera que los nuevos no tienen mucha experiencia en la dinámica del convenio social, dificultándolo (Kaufman, 1985; Keck, 1987).

El mayor obstáculo económico para la transición democrática en Sudamérica es el problema de la deuda externa (Stallings \& Kaufman, 1989). La solución que la OECD - a través del FMI, BM, IDB, etc.- propone para la crisis es la concesión de nuevos créditos si se adoptan medidas ortodoxas de estabilización de la economía (el control de salarios y créditos, la reducción del déficit fiscal y la devaluación de la moneda). Tales disposiciones son medidas peligrosas políticamente (Kaufman, 1985). La liberalización de la economía supone la caída de la producción nacional debido a la falta de incentivos a la inversión, el aumento de precios, la reducción de salarios y del gasto social del gobierno (sanidad, educación, pensiones, etc., que ya eran escasos anteriormente, además de la reducción del gasto militar). En general, los empresarios nacionales latinoamericanos, los militares, los intelectuales y sindicatos están absolutamente en contra de los programas de estabilización; en cambio, el sector de las finanzas mantiene una benevolente neutralidad. La deuda es un mal medio ambiente para la democracia, aunque a veces ha servido de justificación para la mala política de los gobiernos -es más fácil culpar a los «poderes imperialistas» que no reconocer la inaptitud política personal (Kettel \& Magnus, 1986).

Sin embargo, deuda y democracia no tienen porque ser incompatibles. Si la transición se realiza mediante los adecuados pactos sociales, la democracia es el mejor camino para solucionar la crisis. Conduce a menos represivas y más estables formas de gobierno, que pueden reducir las desigualdades socia- 
América Latina: últimos estudios en economía y sociología política

les y reestablecer la imagen de las naciones latinoamericanas - aspecto importante de cara al capital exterior-. Sin embargo, por el momento éste no ha sido el caso. La transición está llevándose a cabo de manera lenta, conflictiva, y no muy exitosa. Todo dependerá de la habilidad política de los gobiernos en sus pactos externos con el FMI, así como de los pactos internos con los distintos grupos sociales nacionales. 


\section{BIBLIOGRAFÍA}

La bibliografía que se presenta a continuación es una breve selección de los artículos o libros considerados como más relevantes en el mundo académico anglosajón. Todas las revistas son de fácil acceso en España, y muchos de los libros están traducidos. Los autores aparecen por orden alfabético, y no de importancia. Se ha señalado entre paréntesis cuando los libros analizan un país concreto.

\section{MANUALES GENERALES}

Abel \& Lewis, 1984: Latin America: Economic Imperialism and the state, London: Institute of Latin American Studies.

Munck, R., 1984: Politics and Dependency in the Third World: The case of Latin America, London: Zed.

Preston, 1987: Latin American development, Harlow: Longman.

Roxborough, I., 1979: Theories of underdevepolment, London: MacMillan.

Skidmore \& Smith, 1988: Modern Latin America, Oxford University Press.

\section{Clases SOCIALES}

Becker, G., 1983: The new bourgeoisie and the limits of dependency (Perú), Princenton Univ. Press.

Bergquist, 1986: Labour in Latin America, Standford Univ. Press.

Evans, P., 1979: Dependent Development, Princenton Univ. Press (Brasil).

Johnson, D., 1985: Local bourgeoisies, intermediate strata, and begemony in South America, en Johnson (ed.) Middle classes in dependent countries.

Perlman, J., 1976: The myth of marginality (Brasil). Berkeley: Univ. of California Press.

Portes, A., 1983: «Latin American Class Structures», en Latin American Research Review, vol. XX.

Roberts, B., 1978: Cities of Peasants. London: E. Arnold.

Roxborough, I., 1984: «Unity and diversity in Latin American History», en Journal of Latin American Studies, vol. XVI.

Smith, 1972: Politics and beef in Argentina.

Spalding, H., 1977: Organized labour in Latin America, New York: Harper \& Row. Teichman, J., 1981: «Interest conflict and entrepreneurial support for Peron», en Latin American Research Review, vol. XVI (Argentina).

Zeitlin \& Radcliff, 1975: «Research methods for the analysis of the internal structure of the dominant classes", en Latin American Research Review, vol. X (Chile). 
América Latina: últimos estudios en economía y sociología política

\section{MOVIMIENTOS SOCIALES}

Bergquist, 1986: Labour in Latin America. Standford Univ. Press.

Dunkerley, J., 1984: Rebellion in the Veins (Bolivia). London: Verso.

-, 1988: Power in the Istbmus (Centro America). London: Verso.

González Casanova (ed.), 1984: Historia del movimiento obrero en América Latina, 4 vols. México: S. XXI.

Keck, M., 1987: «El nuevo sindicalismo en la transición de Brasil», en Estudios sociológicos, $\mathrm{n}^{\circ} 13$.

Knight, A., 1985: «The Mexican Revolution: Bourgeois? Nationalist? or just a "Great Rebellion"?", en Butlletin of Latin American Research, vol. IV.

Laclau, E., 1977: Politics and Ideology in Marxist Theory. London: NLB.

Levine, D. (ed.), 1986: Religion and Political conflict in Latin America (Venezuela y Colombia). Princenton Univ. Press.

Merkx \& Valdés, 1972: "Revolution, conciousness and class: Cuba and Argentina», en Bonachea y Valdés (eds.): Cuba in Revolution. New York: Anchor Books.

Paige, J., 1975: Agrarian Revolution (Perú). New York: McMillan.

Roxborough, I., 1984: Unions and Politics in Mexico, Cambridge Univ. Press.

-, 1989: "Theories of Revolution: The evidence from Latin America», en London School of Economic Quaterly, vol. III.

Slater, D., 1985: New social movements and the state in Latin America. Amsterdam: CEDLA.

Spalding, H., 1977: Organized Labour in Latin America. New York: Harper \& Row.

\section{ESTADO, AUTORITARISMO Y DEMOCRATIZACIÓN}

Ames, B., 1987: Political survival. California Univ. Press.

Canak, W., 1984: "The peripheral state debate: State capitalism and Authoritarian regimes in Latin America», en Latin American Research Review, XIX.

Collier, D. (ed.), 1979: The new authoritarianism in Latin America (ver especialmente el artículo de O'Donnell y la crítica de Serra). Princenton Univ. Press.

Gentleman, J., 1987: Mexican Politics in Transition.

Gillispie, C., 1989: «Democratic consolidation in Latin America», en Third World Quaterly, April.

Hamilton, N., 1982: The limits of the state autonomy. Princenton Univ. Press.

Huntington, S., 1968: Political order in changing societies. Yale Univ. Press.

Malloy \& Selingson (eds.), 1987: Authoritarians and democrats.

McDonough, 1981: Power and ideology in Brazil. Princenton Univ. Press.

O'Brien \& Cammarck (eds.), 1984: Generals in Retreat. Manchester Univ. Press.

O'Donnell, Schmitter \& Whitehead (eds.), 1987: Transitions from the authoritarian rule (5 vols., uno dedicado a América Latina). (Ver especialmente los artículos de Przeworski, Kaufmann, y de los editores). Baltimore: J. Hopkins Univ.

Smith, P., 1979: Labyrinths of power. Princenton Univ. Press (México).

Teichman, 1988: Policymaking in Mexico. London: Allen \& Unwin. 
«Papers»: Revista de Sociologia

\section{DESARROLLO Y DEUDA}

Bennet \& Sharpe, 1985: Transnational corporations versus the state. Princenton Univ. Press.

Booth, D., 1981: «Marxism and development sociology: interpreting the impasse», en World Development, 13.

Bossert, 1986: «The promise of theory» en Klaren \& Bossert (eds.), Promise of development. Boulder: Westview.

Butterworth \& Chance, 1981: Latin American Urbanization. Cambridge Univ. Press.

Cox, R., 1979: «Ideologies and the NIEO», en International Organizations, vol. XXXIII, 2.

Evans, P., 1979: Dependent Development. Princenton Univ. Press.

Evans \& Stephens, 1988: «Development since the sixties: The emergence of a new comparative political economy" en Theory and Society, 17.

Foster Carter, A., 1984: «Theory of development: Current trends» en Third World Book Review, 1.

Grindle, M., 1986: State and countryside: Development policy and agrarian politics in Latin America. Baltimore: J. Hopkins, Univ. Press.

Hernando de Soto, 1989: The other path (Sector informal en Perú), London: Tauris $\&$ Co.

Haggard, 1985: «The politics of adjustment: Lessons from the IMF extended fund facility» en International Organizations, 39, Summer.

Harris, N., 1987: The end of the Third World. London: Tauris.

Kahler, M., 1985: «Politics and International debt: explaining the crisis» en International Organizations, 39, Summer.

Kaufman, R., 1985: «Democratic and authoritarian responses to the debt issue» en International Organizations, 39, Summer.

Kettel \& Magnus, 1986: The international debt game. London: Graham \& Trotman.

Mesa-Lago, C.: «Social Security and development in Latin Amcrica», en CEPAL Review, $\mathrm{n}^{\circ} 28$.

Moran, Th., 1985: Multinational corporations.

Morley, S., 1982: Labour markets and inequitable growth. Cambridge Univ. Press. Moser, C., 1978: «Informal sector or petty commodity production», en World Development, vol. VI, 9.

-, 1986: A theory and methodology of gender planning. London: Univ. College.

O'Brien, 1986: "The debt cannot be paid", en Journal of Latin American Research, 5.

Palma, G., 1981: «Dependency and development: A critical Overvicw», en SF.FRS (ed.), Dependency Theory: A critical reassesment, London: Francis Pinter.

Preston, 1987: Latin American development, Longman.

Redclift, 1987: Sustainable development: Exploring the contradictions. London: Methuen.

Roxborough, I., 1979: Theories of underdevelopment. London: McMillan.

Sanbrook, R., 1982: The politics of basic needs. London: Heineman.

Stallings \& Kaufmann (eds.), 1989: Debt and Democracy in Latin America. Boulder: Westview Press. 
América Latina: últimos estudios en economía y sociología política

Story, D., 1986: Industry, the state and public policy in Mexico. Austin, University of Texas Press.

Strange, S., 1987: States and markets. London: Pinter Publ.

Thorp \& Whitehead (eds.), 1979: Inflation and stabilization in Latin America.

-, 1986: The crisis of debt and adjustment in Latin America. Oxford: McMillan Press.

Warren, B., 1980: Imperialism: Pioneer of capitalism. London: Verso. 